\title{
INDEKS AKTIVITAS LITERASI MEMBACA PESERTA DIDIK DAN PRESTASI AKADEMIK: STUDI KORELASI PADA 34 PROPINSI DI INDONESIA
}

Balai Diklat Keagamaan Medan Jl. TB. Simatupang No. 122 Medan Telp. (061)8456256

E-mail: agustinadjihadi.ad@gmail.com Naskah diterima: 18 November 2021 Naskah Direvisi: 19-20 Oktober 2021 Naskah disetujui: 3 Desember 2021 Website Jurnal: http://apicbdkmedan.kemenag.go.id.

\author{
Agustina
}

\begin{abstract}
ABSTRAK
Upaya pemerintah Indonesia dalam memberantas angka buta aksara patut mendapat apresiasi, namun hal ini tidak dibarengi dengan upaya yang sukses dalam membangun budaya baca masyarakat. Hal ini sesuai dengan berbagai survei dunia yang mencatat rendahnya tingkat literasi di Indonesia. Terdapat beberapa kajian melalui studi kuantitatif mengenai minat dan kegemaran membaca pada berbagai propinsi di Indonesia, dan hal ini dapat menjadi bahan perbandingan. Salah satu studi yang komprehensif dilakukan oleh Pusat Penelitian Kebijakan Pendidikan dan Kebudayaan, Badan Penelitian dan Pengembangan, Kementerian Pendidikan dan Kebudayaan yang merilis Indeks Aktivitas Literasi Membaca (Indeks Alibaca) pada 34 propinsi di Indonesia. Melihat data ini, hal yang menjadi menarik untuk diteliti kemudian adalah apakah tingkat literasi membaca tersebut memiliki korelasi dengan variabel prestasi akademik peserta didik. Hal ini menjadi penting karena pada akhirnya gerakan literasi sekolah/madrasah ditujukan untuk mencapai tingkat paling tinggi yang melampaui tingkat pembiasaan dan pengembangan, yaitu tingkat pembelajaran. Penelitian ini ditujukan untuk menjawab pertanyaan, 1) Apakah terdapat korelasi positif yang signifikan antara tingkat literasi membaca peserta didik dengan prestasi akademik, pada 34 propinsi di Indonesia? dan 2) Strategi apa yang harus dilakukan sekolah/madrasah untuk meningkatkan tingkat literasi membaca peserta didik dan pada saat yang sama meningkatkan ketercapaian prestasi akademik? Penelitian ini menggunakan pendekatan deskriptif korelasional dengan mengumpulkan data melalui telaah dokumentasi dan wawancara. Hasil menunjukkan bahwa didapat korelasi antara indeks aktivitas membaca dengan prestasi akademik (r) adalah 0,766. Terdapat beberapa gagasan inovasi pula dideskripsikan secara kualitatif sebagai hasil wawancara.
\end{abstract}

Kata kunci: Literasi Membaca, Prestasi Akademik

\section{ABSTRACT}

The Indonesian government's efforts to eradicate illiteracy deserve appreciation, but this has not been accompanied by successful efforts in building a reading culture in the community. This is in accordance with various world surveys that note the low level of literacy in Indonesia. There are several studies through quantitative studies on interest and fondness for 
reading in various provinces in Indonesia, and this can be used as comparison material. One of the comprehensive studies conducted by the Center for Policy Research on Education and Culture, Research and Development Agency, Ministry of Education and Culture released the Reading Literacy Activity Index (Alibaca Index) in 34 provinces in Indonesia. Seeing this data, what becomes interesting to study later is whether the reading literacy level has a correlation with the student's academic achievement variable. This is important because in the end the school/madrasah literacy movement is aimed at achieving the highest level that goes beyond the level of habituation and development, namely the level of learning. This study aims to answer the questions, 1) Is there a significant positive correlation between students' reading literacy levels and academic achievement, in 34 provinces in Indonesia? and 2) What strategies should schools/madrasahs do to increase students' reading literacy levels and at the same time increase the achievement of academic achievement? This study uses a descriptive correlational approach by collecting data through the study of documentation and interviews. The results showed that the correlation between reading activity index and academic achievement $(r)$ was 0.766 . There are several innovation ideas also described qualitatively as a result of interviews.

Keywords: Reading Literacy, Academic Achievement

\section{PENDAHULUAN}

Masyarakat literat (literat society), masyarakat berpengetahuan (knowledge society), dan masyarakat yang memiliki budaya baca (reading society), merupakan sebuah penanda penting kemajuan sebuah bangsa. Membangun masyarakat literat, dimana masyarakatnya memiliki minat tinggi terhadap ilmu pengetahuan dan teknologi, seringkali diartikan sebagai upaya membangun peradaban dan masa depan bangsa. Bahkan, Joesoef (2004) menyebutkan bahwa, "Demokrasi hanya akan berkembang, apalagi survive, di suatu masyarakat yang para warganya adalah pembaca, individu-individu yang merasa perlu untuk membaca, bukan sekadar pendengar dan gemar berbicara".

Upaya pemerintah Indonesia dalam memberantas angka buta aksara patut mendapat apresiasi, namun hal ini tidak dibarengi dengan upaya yang sukses dalam membangun budaya baca masyarakat. Masyarakat Indonesia seringkali disebut lebih terbangun budaya lisannya ketimbang budaya membacanya; lebih suka berbicara daripada membaca, lebih suka menonton televisi daripada menulis. Hal ini sesuai dengan berbagai survei dunia yang mencatat rendahnya tingkat literasi di Indonesia. Beberapa temuan dari (1) PIRLS (Progress in International Reading Literacy), yaitu uji literasi membaca yang mengukur aspek memahami, menggunakan, dan merefleksikan hasil membaca dalam bentuk tulisan di tahun 2011, Indonesia menduduki urutan ke-45 dari 48 negara peserta dengan skor 428 dari skor rata-rata 500 (Mullis, I. V. S., dkk., 2012), (2) UNESCO tahun 2012 mencatat bahwa kebiasaan membaca masyarakat Indonesia berada pada kategori rendah, yaitu 1: 1.000 penduduk (Wiedarti dkk., 2016); dan (3) PISA (Programmme for International Student Assesment) yaitu uji literasi membaca pada tahun 2012, Indonesia berada di ranking ke-64 dari 65 negara dengan skor 396, dengan skor ratarata OECD 496 (OECD, 2014).

Menyikapi rendahnya tingkat literasi tersebut, Kementerian Pendidikan dan Kebudayaan telah menerbitkan Peraturan Menteri Pendidikan dan Kebudayaan (Permendikbud) Nomor 23/2015 tentang Penumbuhan Budi Pekerti, dimana salah 
satu tujuannya berupaya untuk memperkuat budaya literasi siswa. Sejak regulasi ini diluncurkan, banyak sekolah mulai menerapkan kegiatan pembiasaan 15 menit membaca buku non-pelajaran sebelum waktu belajar dimulai. Tahun 2016 program Gerakan Literasi Nasional yang terdiri dari Gerakan Literasi Sekolah (GLS), Gerakan Literasi Keluarga, dan Gerakan Literasi Masyarakat juga menyusul diluncurkan. Kementerian Agama juga telah membuat Gerakan Literasi Madrasah (Gelem) sebagai salah satu program Ayo Membangun Madrasah. Upaya-upaya ini diharapkan dapat meningkatkan tingkat literasi membaca peserta didik, meskipun dalam pelaksanaannya seringkali masih mendapati banyak kendala. Implementasi GLS/M merupakan sebuah proses agar siswa menjadi literat, warga sekolah menjadi literat, yang akhirnya literat menjadi kultur atau budaya yang dimiliki individu atau sekolah/madrasah tersebut (Laksono dkk., 2018: 3).

Terdapat beberapa kajian melalui studi kuantitatif mengenai minat dan kegemaran membaca pada berbagai propinsi di Indonesia, dan hal ini dapat menjadi bahan perbandingan. Salah satu studi yang komprehensif dilakukan oleh Pusat Penelitian Kebijakan Pendidikan dan Kebudayaan, Badan Penelitian dan Pengembangan, Kementerian Pendidikan dan Kebudayaan yang merilis Indeks Aktivitas Literasi Membaca (Indeks Alibaca) pada 34 propinsi di Indonesia. Dalam laporannya, ditemukan bahwa 9 provinsi (26\%) masuk dalam kategori aktivitas literasi sedang (angka indeks antara 40,01 - 60,00); 24 provinsi (71\%) masuk kategori rendah (20,01-40,00); dan 1 provinsi (3\%) masuk kategori sangat rendah $(0-20,00)$ (Solihin dkk., 2019). Ini berarti sebagian besar propinsi berada pada level aktivitas literasi rendah dan tidak satu pun propinsi termasuk ke dalam level aktivitas literasi tinggi dan sangat tinggi (nilai indeks antara $60,01-80,00$ dan 80,01-100,00). Hal ini sejalan dengan capaian Indeks Alibaca Nasional yang juga berada di level aktivitas literasi rendah (angka indeks 37,32).

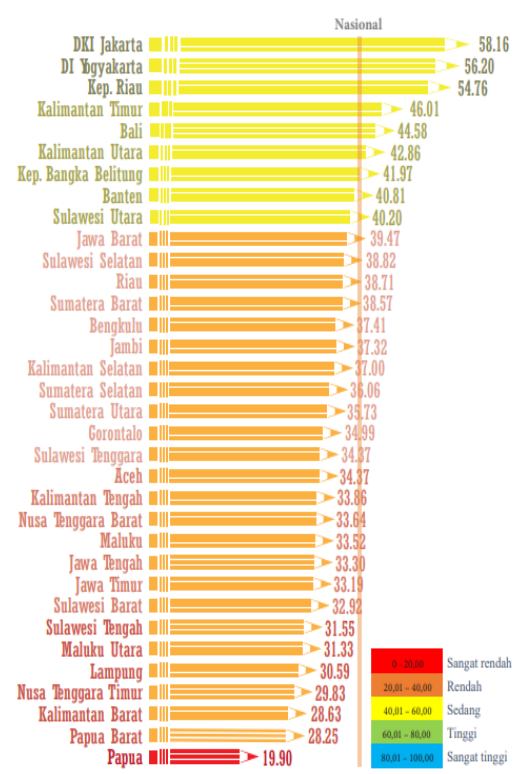

Gambar 1. Indeks Alibaca Propinsi menurut peringkat

Sumber: Solihin, 2016: h.58

Hasil perhitungan indeks provinsi pada Grafik 1 di atas menunjukkan peringkat 3 provinsi dengan nilai indeks tertinggi, yaitu Provinsi DKI Jakarta, D.I. Yogyakarta dan Kepulauan Riau. Meskipun demikian, tiga provinsi tersebut belum mencapai kategori aktivitas literasi tinggi karena indeks ketiganya belum melampaui angka 60,01 atau dengan kata lain masih berada di level aktivitas literasi sedang. 
Melihat data ini, hal yang menjadi menarik untuk diteliti kemudian adalah apakah tingkat literasi membaca tersebut memiliki korelasi dengan variabel prestasi akademik peserta didik. Hal ini menjadi penting karena pada akhirnya gerakan literasi sekolah/madrasah ditujukan untuk mencapai tingkat paling tinggi yang melampaui tingkat pembiasaan dan pengembangan, yaitu tingkat pembelajaran. Pada tingkat pembelajaran, gerakan literasi sekolah/madrasah ditujukan untuk mengembangkan kemampuan siswa berpikir kritis, mampu mengolah kemampuan komunikasi secara kreatif, mampu mengembangkan kemampuan memahami teks dan mengaitkannya dengan pengalaman pribadi.

Wells dalam Heryati, dkk (2010, hlm. 46) juga menyebutkan bahwa terdapat empat tingkatan literasi, yaitu performative, functional, informational, dan epistemic. Literasi tingkat performatif adalah peserta didik sekadar mampu membaca dan menulis, pada tingkat fungsional peserta didik telah menunjukkan kemampuan menggunakan bahasa untuk keperluan hidup atau skill for survival (seperti membaca manual, mengisi formulir), pada tingkat informatif peserta didik telah menunjukkan kemampuan untuk mengakses pengetahuan. Pada literasi tingkatan tertinggi yaitu epistemik, peserta didik telah menunjukkan kemampuan mentransformasikan pengetahuan. Hal ini berarti, jika tingkat literasi membaca peserta didik telah mencapai tingkat yang semakin tinggi, peserta didik dimungkinkan akan meningkat pula pengetahuannya secara umum.

Banyak pendapat para ahli menyebut bahwa perkembangan literasi membaca sangat erat kaitannya dengan perkembangan intelektual seseorang. Schmoker (2012:64) "membaca dan menulis jika dikombinasikan, memberikan kontribusi luar biasa terhadap kecerdasan kritis". Dengan demikian kemampuan literasi sangatlah penting bagi siswa untuk meraih keberhasilan hasil belajar. Terkait dengan teori ini, telah ada beberapa penelitian yang relevan. Sujana, dkk. (2017) pernah melakukan penelitian Eksperimen Metode Baca Good Reading dan Reading Habit untuk meningkatkan kemampuan membaca peserta didik dan hubungannya terhadap prestasi akademik di SMPN 1 Cileunyi Kabupaten Bandung, dengan hasil korelasi positif yang signifikan. Amri dan Rochmah (2021) meneliti tentang pengaruh kemampuan literasi membaca terhadap prestasi belajar siswa sekolah dasar dengan temuan terdapat pengaruh signifikan walaupun hanya sebesar 5,4\% antara kemampuan literasi membaca dengan prestasi belajar siswa. Suandewi, et.al (2019) meneliti hubungan budaya literasi (baca-tulis) dengan hasil belajar bahasa Indonesia siawa kelas XI SMA Negeri 7 Denpasar dengan temuan terdapat hubungan positif dan signifikan dengan beta positif 0,843. Hal ini berarti semakin meningkat budaya literasi akan semakin meningkatkan hasil belajar Bahasa Indonesia. Lalu Puspitasari (2015) meneliti hubungan Kemampuan Literasi dengan Hasil Belajar Siswa Kelas V di SDN Bunulrejo 3 Kota Malang dengan temuan bahwa Subvariabel kemampuan membaca (X1) dan sub-variabel kemampuan menulis (X2) secara bersama-sama berhubungan positif dengan variabel hasil belajar siswa (Y). Dalam skup yang lebih luas, penulis bertujuan untuk menginvestigasi apakah tingkat literasi membaca pada 34 propinsi di Indonesia memiliki korelasi yang positif dan signifikan terhadap prestasi akademik peserta didik yang diukur menggunakan nilai rata-rata ujian akhir nasional.

Berdasarkan latar belakang diatas, penulis merumuskan permasalahan dalam pertanyaan berikut ini, 1) Apakah terdapat korelasi positif yang signifikan antara tingkat literasi membaca peserta didik dengan prestasi akademik, pada 34 propinsi di Indonesia?, dan 2) Strategi apa yang harus 
dilakukan sekolah/madrasah untuk meningkatkan tingkat literasi membaca peserta didik dan pada saat yang sama meningkatkan ketercapaian prestasi akademik? Adapun penelitian ini ditujukan untuk pengambil kebijakan di tingkat pusat untuk mengevaluasi dan merencanakan program literasi yang lebih tepat dan terencana dengan merujuk pada data empiris (evidence based), bagi pemerintah provinsi untuk menjadi gambaran sejauh mana tingkat aktivitas literasi masyarakat di daerah mereka dibandingkan dengan provinsi lain untuk menjadi referensi peningkatan aktivitas literasi masyarakatnya, dan bagi para guru dan pelaku pendidikan untuk menjadi pemacu guna mendorong dan mengawal upaya untuk meningkatkan aktivitas literasi dan dalam saat yang sama meningkatkan prestasi akademik peserta didik di daerah masing-masing.

\section{METODOLOGI PENELITIAN}

Penelitian ini menggunakan pendekatan deskriptif korelasional, yaitu penelitian yang diarahkan untuk menjelaskan hubungan antara dua variabel bebas dengan variabel terikat dengan disain penelitian cross-sectional, dimana data yang menyangkut variabel bebas dan terikat dikumpulkan dalam waktu bersama-sama (Notoatmodjo, 2010). Sampel diambil dengan teknik comprehensive sampling yaitu pemilihan sampel dengan menggunakan seluruh populasi yang ditentukan, dalam hal ini seluruh propinsi di Indonesia. Data dikumpulkan dengan dua teknik, yaitu 1) melalui telaah dokumentasi, dalam hal ini data Indeks Aktivitas Membaca yang bersumber dari studi Pusat Penelitian Kebijakan Pendidikan dan Kebudayaan, Badan Penelitian dan Pengembangan, Kementerian Pendidikan dan Kebudayaan, dan Nilai rata-rata Ujian Nasional tingkat SMP/MTs pada 34 Propinsi yang bersumber dari, dan 2) melalui wawancara terbuka dengan para pakar sebagai responden. Dalam wawancara ini, yang menjadi responden adalah Isah Cahyani (Instruktur Nasional Literasi Membaca AKMI Kementerian Agama dan dosen Pendidikan Bahasa Indonesia Universitas Pendidikan Indonesia) dan Dian Khairani (Guru Bahasa Inggris di Palembang, pelaku literasi).

Data yang telah dikumpul melalui dua teknik tersebut dianalisis dengan dua teknik, yaitu 1) analisis bivariate, yaitu analisis untuk menguji dua variabel yang diduga memiliki korelasi (Notoatmodjo, 2010), dan 2) hasil wawancara dianalisis secara deskriptif kualitatif dengan display data melalui grafik, merujuk pada teknik analisis data kualitatif Miles dan Huberman (1992).

\section{HASIL DAN PEMBAHASAN}

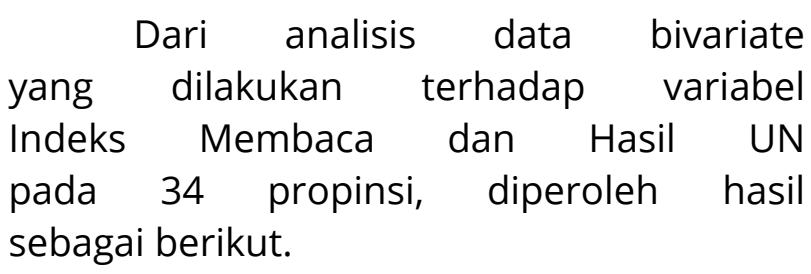

Tabel 1. Korelasi indeks membaca dan hasil UN

\begin{tabular}{llrr}
\hline \multicolumn{4}{c}{ Correlations } \\
\hline & & Indeks Membaca & Hasil UN \\
\hline Indeks Membaca & Pearson Correlation & 1.000 & .766 \\
\hline & Sig. (2-tailed) & 34 & .004 \\
\hline & $\mathrm{N}$ & .766 & 34 \\
\hline Hasil UN & Pearson Correlation & .004 & 1.000 \\
\hline & Sig. (2-tailed) & 34 & 34 \\
\hline
\end{tabular}


Dari hasil analisis korelasi sederhana ( $r$ ) didapat korelasi antara indeks aktivitas membaca dengan prestasi akademik ( $r$ ) adalah 0,766. Nilai korelasi yang diperoleh antara kedua variable tersebut masuk dalam kategori tingkat. Hal ini menunjukkan bahwa terjadi hubungan yang kuat antara indeks aktivitas membaca dengan prestasi akademik ( $r$ ). Sedangkan arah hubungan adalah positif karena nilai $r$ positif, hal ini dapat diartikan bahwa, semakin tinggi indeks aktivitas membaca maka semakin meningkatkan prestasi belajar.

Adapun dari hasil wawancara gagasan program peningkatan literasi membaca yang dapat diterapkan di sekolah/madrasah adalah sebagai berikut: 1) mengadakan Book Day, yaitu satu hari pada tiap 2 pekan dimana siswa harus berinteraksi dengan buku dalam sesi review sharing buku favorit yang telah selesai dibaca dan merekomendasikannya dengan teman-teman yang lain; 2) mengadakan sesi kelas khusus untuk anak-anak yang punya bakat menulis untuk menulis buku antologi yang difasilitasi penerbitannya oleh madrasah. Hal ini dapat mendorong peserta didik untuk tidak cuma jadi pembaca tapi juga menuliskan karyanya; 3) mengadakan Festival Literasi, yaitu stand buku-buku murah, lomba sinopsis buku, lomba menulis puisi tematik, sesi bedah buku dan lain-lain; 4) memberikan dorongan pada para guru untuk selalu menyediakan bahan pembelajaran kaya teks dan mengintegrasikan praktek menganalisis teks dalam pembelajaran; 5) menciptakan lingkungan ramah literasi yang kaya akan teks, adanya display mading yang diperbaraui tiap pecan, ada poster-poster yang dibuat oleh siswa, dan pajangan hasil karya di kelas.

Temuan yang ada dari hasil korelasi yang erat antara indeks membaca peserta didik dan hasil belajarnya, menunjukkan betapa pentingnya meningkatkan literasi membaca karena pada gilirannya akan terkait dengan peningkatan tingkat akademisnya. Hal ini disebutkan juga oleh Anisa dll (2021: 1) bahwa salah satu penyebab pendidikan di Indonesia masih rendah dibanding dengan negara-negara lainnya adalah pengaruh kurangnya literasi atau minat baca pada siswa maupun mahasiswa serta kemampuan dalam berpikir kritis (critical thinking) yang masih rendah. Menurutnya, pembelajaran seharihari di sekolah juga dinilai kurang cukup efektif dalam mengembangkan sebuah minat, bakat, dan potensi yang ada di dalam diri para siswa.

Hal inilah yang membuat gagasan yang disebutkan oleh para praktisi literasi dalam wawancara yang dilakukan penulis menjadi penting untuk dilakukan. Inovasi pengembangan literasi menjadi hal yang urgen. Teori inovasi dalam pendidikan adalah sebuah paradigma tentang suatu unit yang saling terkait dan tidak dapat dipisah-pisahkan antara tiga proses utama pedagogik yang meliputi membuat kebaruan, menguasainya, dan mengaplikasikannya (Stukalenko, dll: 2016). Artinya, inovasi dalam bidang literasi membaca mencakup segala aktivitas yang ada di dalamnya. Mulai dari inovasi kurikulum, strategi pembelajaran, metode pembelajaran, media pembelajaran, dan lain-lain dan hal ini harus menjadi bahan pertimbangan tiap pelaku literasi.

\section{SIMPULAN}

Dari hasil penelitian diperoleh kesimpulan bahwa didapat korelasi antara indeks aktivitas membaca dengan prestasi akademik pada 34 propinsi di Indonesia. Hal ini menunjukkan bahwa terjadi hubungan yang kuat dan positif antara indeks aktivitas membaca dengan prestasi akademik, berarti semakin tinggi indeks aktivitas membaca maka semakin meningkatkan prestasi belajar. Hal ini menjadi catatan untuk dapat menerapkan berbagai inovasi peningkatan literasi dalam tingkat sekolah/madrasah seperti yang diusulkan para praktisi literasi, diantaranya menyelenggarakan Book Day, 
class session menulis antologi buku, lomba sinopsis buku, mengintegrasikan analisis teks dalam pembelajaran, menciptakan lingkungan ramah literasi yang kaya akan teks, dan menyelenggarakan festival literasi. Diharapkan dengan melakukan berbagai inovasi secara konsisten, tingkat literasi membaca peserta didik dapat meningkat dan akan berpengaruh positif pada prestasi akademik peserta didik.

\section{SARAN}

Berdasarkan hasil penelitian, beberapa saran dirumuskan sebagai berikut. Bagi peneliti lebih lanjut direkomendasikan untuk modifikasi variabel-variabel independen baik menambah variabel atau menambah time series datanya, sehingga akan lebih objektif dan bervariasi dalam melakukan penelitian. Bagi sekolah dan madrasah disarankan untuk merumuskan rencana kegiatan literasi sekolah/madrasah yang lebih intensif dalam rangka meningkatkan kompetensi literasi peserta didik. Bagi dinas pendidikan kota dan kantor wilayah dan kota Kemenag disarankan untuk dapat memberikan perhatian lebih ekstra dalam mendukung peningkatan kompetensi literasi di tingkat sekolah/madrasah. Diharapkan sinergi yang baik antara pemerintah dan sekolah/madrasah akan dapat meningkatkan budaya literasi pada tingkat sekolah/madrasah hingga akan berpengaruh pula pada hasil belajar peserta didik.

\section{DAFTAR PUSTAKA}

Anisa, Azmy Risky dkk. (2021) "Pengaruh Kurangnya Literasi serta Kemampuan dalam Berpikir Kritis yang Masih Rendah dalam Pendidikan di Indonesia". Current
Research in Education: Conference

Series Journal Vol. 01 No. 01, 2021.

Amri, Saeful., Eliya Rochmah. EduHumaniora: Jurnal Pendidikan Dasar | p-ISSN 2085-1243 | e-ISSN 2579-5457 Vol. 13 No.1 Januari 2021 | Hal 52-58. Pengaruh Kemampuan Literasi Membaca terhadap Prestasi Belajar Siswa Sekolah Dasar. EduHumaniora: Vol. 13 No. 1, Januari 2021.

Heryati, Y., dkk. (2010). Model Inovatif Pembelajaran Bahasa Indonesia. Jakarta: Multi Kreasi Satudelapan.

Jousoef, Daod, dalam Soelarto dkk. (Peny). Bukuku Kakiku. (2004). Jakarta: PT Gramedia Pustaka Utama.

OECD. (2014). PISA 2009 \& PISA 2012 Results in Focus. Programe for International Student Assesment. Diakses pada 20 Oktober 2021 dari http://www.oecd.org/pisa/keyf indings/pisa-2012resultsoverview.pdf.

Miles, B. Mathew dan Michael Huberman. 1992. Analisis Data Kualitatif Buku Sumber Tentang Metode-metode Baru. Jakarta: UIP.

Mullis, I. V. S., dkk. (2012). PIRLS 2011 International Result in Reading. Diakses pada 20 Oktober 2021, dari

http://timssandpirls.bc.edu/pirl s2011/downloads/P11 IR Ful IBook.pdf.

Notoatmodjo, S. $2010 . \quad$ Metodologi Penelitian Kesehatan. Jakarta : Rineka Cipta.

Suandewi, Pt Melia, Ida Bagus Putrayasa, Gede Gunatama. Hubungan Budaya Literasi (Baca Tulis) dengan Hasil Belajar Bahasa Indonesia Siswa Kelas Xisma Negeri 7 Denpasar. Jurnal Pendidikan Bahasa dan Sastra Indonesia Undiksha. Volume: 9 Nomor: 2, Agustus 2019 P-ISSN: 2614-4743 (cetak) dan e-ISSN: 
2614-2007

(online).

DOI: http://dx.doi.org/10.23887/jjp

bs.v9i2.20453

Solihin, Lukman., dkk. (2019). Pusat Penelitian Kebijakan Pendidikan dan Kebudayaan Badan Penelitian dan Pengembangan, Kementerian Pendidikan dan Kebudayaan. Hal 58-59.

https://hasilun.puspendik.kemdikb ud.go.id/

Puspitasari, Esthi Prasetyaning. 2015. Hubungan Kemampuan Literasi dengan Hasil Belajar Siswa Kelas V di SDN Bunulrejo 3 Kota Malang. Skripsi, Program Studi Pendidikan Guru Sekolah Dasar, Jurusan Kependidikan Sekolah Dasar dan Prasekolah, Fakultas IImu Pendidikan, Universitas Negeri Malang.
Schmoker, M. (2012). Menjadi Guru yang Efektif; Bagaimana Mencapai Pembangunan Baru Melalui Membaca dan Menulis. Jakarta: Erlangga

Stukalenko, N. M., Zakhina, B. B., Kukubaeva, A. K., Smagulova, N. K., \& Kazhibaeva, G. K. (2016). Studying Innovation Technologies in Modern Education. International Journal of Environmental \& Science Education, 11(15), 7297-7308.

Wiedarti, dkk. (2016). Desain Induk Gerakan Literasi Sekolah. Jakarta: Direktorat Jenderal Pendidikan Dasar Dan Menengah Kementerian Pendidikan Dan Kebudayaan. 